\title{
Differences among Somatotype, Body Composition and Energy Availability in Mexican Pre-Competitive Female Gymnasts
}

\author{
Adriana Poblano-Alcalá*, Debbie Braun-Zawosnik \\ Department of Nutrition, Mexican Olympic Committee and School of Nutrition, \\ Iberoamerican University, Mexico City, Mexico \\ Email: ${ }^{*}$ adri_poblano@hotmail.com
}

Received 6 November 2013; revised 6 December 2013; accepted 14 December 2013

Copyright $(2014$ by authors and Scientific Research Publishing Inc.

This work is licensed under the Creative Commons Attribution International License (CC BY). http://creativecommons.org/licenses/by/4.0/

(c) (i) Open Access

\begin{abstract}
Gymnastics is a discipline that has some factors that differentiate from other sports, such as: force, postural control on movement, extreme range of motion, and of the body expression. The objective of the present paper was to compare: somatotype, body composition and energy availability in female gymnasts students in search for a better sport performance. We evaluated 24 healthy female children aged 7 - 12 years by means of a nutritional and anthropometric examinations, somatotype and body composition calculation, and energy availability measurement. We observed a low consumption of real calories intake, carbohydrates, and low amount of the real body weight mesurements among gymnatics students. Mesomorphic and ectomorfic somatotypes were the more frequent somatotypes found. Moreover, we saw significant differences in body composition and in energy availability among the differente somatotypes in student of gymnastics. Differences were located between endomorphic, mesomorphic, and ectomorphic somatotype groups in body composition while in energy availability were among mesomorphic-ectomorphic, and between endomorphic-ectomorphic groups. In conclusion, our data had important implications for performance of gymnastics in students and were discussed here.
\end{abstract}

\section{Keywords}

Gymnastics; Somatotype; Body Composition; Energy Availability

\section{Introduction}

Gymnastics is a discipline of serial complex exercise activities that have some factors that differentiate from "Corresponding author.

How to cite this paper: Poblano-Alcalá, A. and Braun-Zawosnik, D. (2014) Differences among Somatotype, Body Composition and Energy Availability in Mexican Pre-Competitive Female Gymnasts. Food and Nutrition Sciences, 5, 533-540. 
other sports. These are the force, postural control on movement, extreme range of motion, and of the body expression. The physiologic requirements of gymnastics reflect a muscular load and exercise comparable to other sports; for example, athletics and others that have been defined as predominantly type of exercise, in which explosive bursts of exercise are followed by moments requiring precision and skill. For that reason, it has been suggested that gymnasts would benefit from a good aerobic foundation and high anaerobic threshold to limit the effects of blood lactate accumulation such as a decrease in balance, poise, and coordination [1].

Sheldon (1940) proposed that the human physique and body could be classified according to the contribution of three fundamental somatotypes. Their supposed associated physical traits can be summarized as follows: Ectomorphic somatotype: characterized by long and thin muscles/limbs and low fat storage; usually referred to as slim. Mesomorphic somatotype: characterized by medium bones, solid torso, low fat levels, wide shoulders with narrow waist, referred as muscular. Endomorphic somatotype: characterized by increased fat storage, a wide waist and a large bone structure, usually referred to as fat [2]. Sheldon categorised body types according to a scale ranging from 1 to 7 for each of the three "somatotypes", where the pure "endomorph" is 7-1-1, the pure "mesomorph" 1-7-1 and the pure "ectomorph" scores 1-1-7, respectively.

Boby composition in general people and athlets is used to describe the percentages of fat, bone and muscle in human bodies. Because muscular tissue takes up less space in our body than fat tissue, our body composition, as well as our weight, determines leanness [3]. The National Institute of Health of United States of America recommends that a healthy adult male's body should have between $6 \%-24 \%$ of fat and a female should have $14 \%$ - 31\%. Levels above these amounts may indicate excess body fat. Athletes such as gymnasts, leaner individuals, and more muscular individuals will have a body fat percentage lower than these levels [4]. In general, most athletes experience greater performance benefits at body fat percentages between $7 \%$ - 19\% for men, and 10\% - 25\% for women, depending on the sport.

Energy availability is supported mainly as glycogen stores in skeletal muscle. The importance of glycogen as a fuel during exercise has been recognized; however, little is known about the precise mechanism that relates skeletal muscle glycogen to muscle fatigue. Low muscle glycogen is associated with an impairment of muscle ability to release $\mathrm{Ca}\left({ }^{2+}\right)$, which is an important signal in the muscle activation. Thus, depletion of glycogen during prolonged, exhausting exercise may contribute to muscle fatigue by causing decreased $\mathrm{Ca}\left({ }^{2+}\right)$ release inside the muscle. These data provide indications of a signal that links energy utilization, i.e. muscle contraction, with the energy content in the muscle, inhibiting a detrimental depletion of the muscle energy store during exercise [5].

The objective of the present paper is to compare: body composition and energy availability in female gymnasts students with different somatotypes, because contemporary gymnastics exercises are becoming more difficult and demanding, thus, knowledge of how these conditions influence sport performance allows nutricians and professionals involved in the care of athletes, to provide adequate nutritional recommendations when looking for better results in national and/or international sport competitions.

\section{Material and Methods}

\subsection{Subjects}

We evaluated 24 healthy female children aged 7 - 12 years who were students at the Gymnastics School of the Mexican Olympic Committee. The children were examined at the Clinic of Nutrition of the Mexican Olympic Committee and they were included in the Prospective study protocol of Nutrition for Athletes of the Mexican Olympic Committee in Mexico City. Inclusion criteria were the following: healthy clinically female children, as determined by a medical clinical examination; being a regular student in the Gymnastics school; absence of congenital or metabolic alterations. Parent of children received a class of "Importance of nutrition in sport children". Parents and children were widely informed about the study and the importance of their participation in it. This investigation was approved by the Research and Ethics Committee of the Mexican Olympic Committee and of the Iberoamerican University, and informed consent was signed by the parents or guardians of participating children.

\subsection{Nutritional Examination}

Chidren were evaluated before the training course by means of a Clinical-Nutritional History with a 24 hr recordatory, measuring real consumption of kilocalories, carbohydrates, proteins, and lipids. Data from each chil- 
dren were compared with those of the Mexican System of Equivalent Foods standards [6], based in the Mexican Official Norm: NOM-043-SSA2-2005, Basic Health Services, Promotion and health education in foods. Criteria to provide orientation [7], and were individually qualified.

\subsection{Anthropometric Examination}

We performed an anthropometric examination by means of measuring the main anthropometric measures (i.e.: height $[\mathrm{cm}]$, weight $[\mathrm{Kg}]$, and, $B M I$ ). $B M I$ is a measure from the human body shape based on an individual's mass and height with the following equation: $B M I=$ mass $(\mathrm{Kg}) /[\text { height }(\mathrm{m})]^{2}$. Moreover, we assessed the following measures: tricipital, subescapular, supraspinal, and calf skin folds (mm); contracted arm and calf perimeters $(\mathrm{cm})$; humeral and femoral biepicondilar diameters $(\mathrm{cm})$. We utilized a Caliper for skin folds Slim Guide, a small slip Caliper Futrex (Maryland, USA), and a metalic anthropometric scale Lufkin model W606 (Michigan, USA). To perform with this objective, the main author (APA) recived a training course and certification of the International Society for the Advancement of Kinanthropometry.

\subsection{Somatotype Calculation}

Somatotype calculation and analysis was performed with the help of the Somatotype Calculation and Analysis program for MacOS X 1.2.2. After having entered data as name, gender, endomorphy, mesomorphy, and ectomorphy, program calculates automatically: Somatotype attitudinal distance, somatotype attitudinal mean, and somatotype analysis of variance from Carter and Heath charts.

\subsection{Boby Composition}

We used three variables selected for its representativity of the body composition taking in account age of subjects, as follows: weight, height, and BMI. Measurements were performed with a Stadimeter Seca (Hamburg, Germany) model 202, and Tanita weight scale (Tokyo, Japan) model BF679W according with the International Standards.

\subsection{Energy Availability}

We calculated the total calories intake from the $24 \mathrm{hr}$ recordatory and compared this in each subject with the data from tables of the total ideal of calories intake obtainded by the energy availabillity method [8]. This last variable was obtained with the measurement of calories spent during exercice session by means of a CardiacMetabolic monitor (Polar ${ }^{\circledR}$, Oulu, Finland), and with calculation of FFM index with the following equation:

$$
\text { Fat-free mass = body weight }(\mathrm{Kg})-\text { body fat mass }(\mathrm{Kg})
$$

Body fat mass was assessed from total body density and measures of skinfold thickness. We determined an asigned value, in base that the objective of our subjects was mantaining body weight at $45 \mathrm{kcal} / \mathrm{kg}$ of FFM/day. We calculated energy availability by the following equation:

Energy availibility $=$ kcal spent in exercice + FFM $\times$ asigned value according to objective

In this way, we obtained values for ideal and real energy intake by each subjects for comparison purpose.

\subsection{Statistics}

We measured the mean and Standard deviation of continuous variables and percentages in binomial variables. Continuous variables were compared by means of the $t$ of Student test. We used one-way Analysis of variance to compare the means of three or more groups, with Tukey Honestly Significant Difference post-hoc test to locate differences between groups. The $a$-priori alpha value accepted was $p \leq 0.05$. We utilize SPPS software version 17.0.

\section{Results}

\subsection{Nutritional Examination}

Average of the amount of real calories intake in our studied female gymnasts was $1773.43 \mathrm{kcal} / \mathrm{d}(\mathrm{SD}=714.73)$, 
while ideal amount of calories intake was $2449.80 \mathrm{kcal} / \mathrm{d}(\mathrm{SD}=276.12)$. Difference between real and ideal intake was significant lower than expected for age and activity in the sample $(t=-3.90, p=0.001)$. We observed that in 16 subjects the real intake of calories was lower than the ideal amount, although five subjects comsumed a higher amount than the real intake, and in three subjects the real intake was in agreement with the ideal intake. Differences among real to ideal intake of carbohydrates from the studied gymnasts was also significant lower than expected $(t=-5.40, p<0.001)$. However, differences among real and ideal intake of proteins showed no significant differences $(t=-1.99, p=0.06)$. Differences among real and ideal intake of lipids was also no significant $(t=-1.16, p=0.25)$, see Table 1 .

\subsection{Body Composition}

Difference between real and ideal body weight measurements, was significantly lower for the real measurement $(t=-4.19, p=<0.001)$. Difference comparison was also significant for real height measurement $(t=-4.31, p=<$ 0.001). However, comparison between real to ideal BMI was no significant $(t=0.39, p=0.70)$. See Table 2 .

\subsection{Somatotype}

Endomorphic somatotype were found in four subjects, we found in this group a difference of -2.52 in the somatotype chart (SD = 0.47); Mesomorphic mean component difference was -0.89 (SD = 0.86); Ectomophic component showed a difference of $-0.74(\mathrm{SD}=1.19)$. See Table 3 .

Mesomorphic somatotype were found in ten girls with a difference of 0.28 (SD $=0.83$ ); Endomorphic component for this group disclosed a difference of 0.95 ( $S D=0.19$ ); Ectomorphic component showed a difference of $1.42(\mathrm{SD}=0.66)$. See Table 3.

Ectomorphic somatotype were found in seven subjects with a difference of -0.84 (SD = 1.43); Endomorphic component for this group showed a difference of 1.07 ( $\mathrm{SD}=0.62$ ); Mesomorphic component presented a difference of $0.53(\mathrm{SD}=0.89)$. See Table 3 .

Table 1. Differences between real to ideal amount intake of nutrients in the sample.

\begin{tabular}{cccc} 
& Real intake (g) & Ideal intake (g) & $p$ \\
\hline Carbohydrates & $\mathrm{x} \pm \mathrm{SD}$ & $\mathrm{x} \pm \mathrm{SD}$ & $*$ \\
Proteins & $246.92 \pm 91.46$ & $368.54 \pm 34.14$ & $\mathrm{~ns}$ \\
Lipids & $77.82 \pm 27.28$ & $90.79 \pm 10.39$ & $\mathrm{~ns}$ \\
\hline
\end{tabular}

$\mathrm{x}=$ average; $\mathrm{SD}=$ Standard deviation; $p=$ alpha probability; ${ }^{*}=$ Statistically significant; $\mathrm{ns}=$ no significant.

Table 2. Differences between real to ideal somatometric measurement.

\begin{tabular}{cccc}
\hline & Real measure & Ideal measure & $p$ \\
\hline Weight (Kg) & $\mathrm{x} \pm \mathrm{SD}$ & $\mathrm{x} \pm \mathrm{SD}$ & \\
Height (m) & $37.39 \pm 9.43$ & $1.47 \pm 0.8$ & \\
BMI & $1.42 \pm 0.9$ & $17.88 \pm 1.35$ & $*$ \\
\hline
\end{tabular}

$\mathrm{x}=$ average; $\mathrm{SD}=$ Standard deviation; $p=$ alpha probability; ${ }^{*}=$ Statistically significant; $\mathrm{ns}=$ no significant; BMI = Body mass index.

Table 3. Measurement of somatotype between groups.

\begin{tabular}{cccc}
\hline & Component & Endomorphic & Mesomorphic \\
\hline Somatotype & & & \\
Endomorphics & $\mathbf{4 . 4 2 \pm \mathbf { 0 . 4 5 }}$ & $2.79 \pm 0.86$ \\
Mesomorphics & $3.65 \pm 0.19$ & $\mathbf{4 . 3 2} \pm \mathbf{0 . 8 3}$ & $3.17 \pm 0.66$ \\
Ectomorphics & $1.82 \pm 0.62$ & $3.74 \pm 0.53$ \\
\hline
\end{tabular}




\subsection{Differences in Body Composition and Energy Availability Acoording to Somatotype}

We saw significant differences in Body composition $(F=14.14, d f=2.18, p<0.001)$, and in Energy availability $(F=4.29, d f=2.18, p=0.03)$ among the differente somatotypes in student of gymnastics. Test of Tukey HSD showed that differences were located between Endomorphic, Mesomorphic, and Ectomorphic somatotype groups in Body composition while in Energy availability were among Mesomorphic-Ectomorphic, and between Endomorphic-Ectomorphic groups.

\section{Discussion}

\subsection{Main Findings}

In this research we showed that the mesomorphic type of somatotype was the more frequent feature found in our studied population, a significant number of gymnastics female students have a low amount of calories and carbohydrates intake than the ideal consumption; their real body weight was low than the ideal body weight. At last, we saw significant differences in Body composition, and in Energy availability among different somatotypes in our female student of gymnastics; differences were mainly between Endomorphic, Mesomorphic, and Ectomorphic groups in Body composition while in Energy availability were among Mesomorphic-Ectomorphic, and between Endomorphic-Ectomorphic groups.

\subsection{Comparison with other Studies}

Somatotype has an important influence in the performance of several sports disciplines [9] [10]. In female gymnastics, somatotype has also an important role [11]. In overall, body morphological features in gymnasts are basic in competitions, because the new requirements in contemporary gymnastics, such as the new exercises that are becoming more difficult including those that require more rotation around the vertical and horizontal axis [12].

Few studies have been performed to search for the influence of somatotype in performance of female gymnasts [13]. In female elite gymnasts, anthropometric data of outstanding gymnasts were gathered on the occasion of the $24^{\text {th }}$ World Championship Artistic Gymnastics [14].

In one study, the contribution of anthropometric characteristics to performance scores in elite female gymnasts was measured. Correlational analysis and a stepwise multiple regression were used. A total of 168 female gymnasts (mean age of $16.5+/-1.8$ years) were investigated. An extensive battery of anthropometric dimensions was taken on each athlete. The somatotype was estimated. Skeletal maturation of the hand-wrist was assessed. Competition scores for the four individual gymnastic events (balance beam, floor exercise, vault, uneven bars) and a composite score for each gymnast were the dependent variables. Significant correlations were observed between skinfolds and endomorphy, and gymnastics performance scores, for biceps skinfold and the score on balance beam, and for endomorphy and the total score, respectively. The correlations suggested that gymnasts with more subcutaneous fat and higher endomorphy have lower performance scores. Endomorphy and chronological age were the most important predictors [15].

In other study, the Health-Carter anthropometric somatotype of gymnasts 13 - 20 years of age were compared with reference data for a nationally representative sample of Belgian girls; elite gymnasts are considerably shorter and lighter with narrower shoulders and hips, but the differences are more apparent after the 17 years; elite gymnasts do not differed from non-athletes in relative leg length, but they have proportionally broader shoulders relative to hips; differences in somatotype occur primarily in endomorphy (especially lower in gymnasts) and to a lesser extent in mesomorphy (higher in gymnasts) [16]. In the contrary direction to researches carried-out with elite gymnasts, our sample was constructed by female pre-competitive students of gymnastics, we observed in they, a higher proportion of girls with endomorphic somatotype (four of 24, 16\%), thus, recommendations of the health care team for this particular group may included a reduction of the bodyweight, in the case that this girls want to participate in national and international competitions.

One study investigated the relationships between specific anthropometric ( 9 skinfolds, 13 girths, 8 lengths and 8 breadths), body composition (body fat \%, FFM, FM) parameters and bone mineral parameters (BMD, BMC) in young rhythmic gymnasts and same age controls; eighty nine 7 - 8-year-old girls participated in this study and were divided to the rhythmic gymnast's and control groups. Body composition was determined by dual energy X-ray absorptiometry (FFM, FM, body fat \%, BMD and BMC). Body fat \% and FM were lower and BMD and 
BMC values at lumbar spine (L2 - L4) and femoral neck were higher in rhythmic gymnasts compared with controls [17].

Level of exercice had an important role in bone and muscle functions, for example Burt, Naughton, Greene, Courteix, and Ducher [18], showed that non-elite gymnastics participation was associated with musculoskeletal benefits in upper limb bone geometry, strength and muscle function. Researchers found differences between two gymnastic groups: the first with high-training and the second with low-training in gymnasts and other group of no-gymnasts girls. High-trained gymnasts showed greater forearm bone strength compared with no-gymnasts, as well as greater arm lean mass, BMC, and muscle function; low-trained gymnasts displayed greater arm lean mass, BMC, muscle power, and endurance than no-gymnasts; however, the difference in bone strength did not reach significance.

In the case of pre-competitive gymnasts, 129 girls (29 gymnasts, 46 ex-gymnasts, and 45 non-gymnasts) between 4 and 9 years of age (mean $=6.8 \pm 1.3$ ) were compared. Bone mass, density, structure, and estimated strength were determined using peripheral quantitative computed tomography at the distal (4\%) and shaft (65\%, $66 \%$ ) sites in the radius and tibia. Total body, hip, and spine BMC was assessed using dual energy X-ray absorptiometry. Analysis of covariance (covariates of sex, age and height) was used to investigate differences in ToC, ToD, ToA, and estimated strength at the distal sites and ToA, CoC, CoD, CoA, cortical thickness, medullary area, and estimated strength at the shaft sites. Gymnasts and ex-gymnasts had 5\% greater adjusted total body BMC and 6\% - 25\% greater adjusted ToC, ToD, and estimated strength at the distal radius compared to non-gymnasts. Ex-gymnasts had 7\% - 11\% greater CoC and CoA at the radial shaft and 5\% - 8\% greater CoC and estimated strength at the tibial shaft than gymnasts and non-gymnasts. Ex-gymnasts also had 12\% - 22\% greater ToC and estimated strenght at the distal tibia compared to non-gymnasts. This data suggests that recreational and precompetitive gymnastics participation is associated with greater bone strength [19].

Energy availability is an important parameter to take account in sport practicing. For example, genetic potential for growth can be fully expressed under favorable environmental conditions. Moderate physical activity has beneficial effects on growth, but excessive physical training may negatively affect it. Sports favoring restricted energy availability, in the presence of high energy expenditure, which are of particular concern for parents and sport trainers. In gymnasts, a different pattern in skeletal maturation and linear growth was observed, resulting in an attenuation of growth potential in artistic gymnasts, more pronounced in males than in females. In female rhythmic gymnasts, the genetic predisposition to growth was preserved owing to a late catch-up growth phenomenon. In all other sports not requiring strict dietary restrictions, no deterioration of growth has been documented so far. Intensive physical training and negative energy balance alter the hypothalamic pituitary set point at puberty, prolong the prepubertal stage, and delay pubertal development and menarche in a variety of sports. In elite gymnasts, prepubertal stage is prolonged and pubertal development is entirely shifted to a later age, following the bone maturation rather than the chronological age [20].

Moreover, energy expenditure is necessary to be controlled in gymnasts during competitions. One study determined dietary intake and energy balance of elite premenarcheal rhythmic gymnasts during their preseason training. Forty rhythmic gymnasts and 40 sedentary age-matched females $(10-12$ years) participated in the study. Anthropometric profile and skeletal ages were determined. Dietary intake and physical activity were assessed to estimate daily energy intake, daily energy expenditure, and resting metabolic rate. Groups demonstrated comparable height, bone age, pubertal development, resting metabolic rate. Gymnasts had lower body mass, BMI, body fat than age-matched controls. Although groups demonstrated comparable daily energy intake, gymnasts exhibited a higher daily energy expenditure resulting in a daily energy deficit. Gymnasts also had higher carbohydrate intake but lower fat and calcium intake. Both groups were below the recommended dietary allowances for fiber, water, calcium, phosphorus and vitamin intake. Thus, this observation is in line with our data, gymnasts may need to raise their daily energy intake to avoid the energy deficit during periods of intense training [21].

\subsection{Study Limitations}

Our study has some limitations. The size of the sample was short, thus, number of studied subjects must be increased. Our observation has a cross-sectional design, a long-term prospective follow-up would make strengthen our results. Thus we must have caution in the interpretation of results and this must be considered only as tendencies. However, these results deserve continue in a long-term follow-up of with greater number of subjects. 


\section{Conclusion}

In conclusion we observed that the mesomorphic type of somatotype was the more frequent characteristic found in gymnastics female students. We observed a lower amount of calories and carbohydrates intake than the ideal consumption and that their real body weight was lower than the ideal body weight. We also saw significant differences in body composition, and in energy availability among different somatotypes in our female student of gymnastics.

\section{References}

[1] Lange, B., Halkin, A.S. and Bury, T. (2005) Physiologic Requirements of High Level Gymnastics. Revue Medicale de Liege, 60, 939-945.

[2] Vertinsky, P. (2007) Physique as Destiny: William H. Sheldon, Barbara Honeyman Heath and the Struggle for Hegemony in the Science of Somatotyping. Canadian Bulletin of Medicine History, 24, 291-316.

[3] Jeukendrup, A. and Cronin, L. (2011) Nutrition and Elite Young Athletes. Medicine and Sport Science, 56, 47-58. http://dx.doi.org/10.1159/000320630

[4] Kumanyika, S.K. and Obarzanek, E. (2003) Pathways to Obesity Prevention: Report of a National Institute of Health Workshop. Obesity Research, 11, 1263-1274. http://dx.doi.org/10.1038/oby.2003.172

[5] Ørtenblad, N., Nielsen, J., Saltin, B. and Holmberg, H.C. (2011) Role of Glycogen Availability in Sarcoplasmic Reticulum $\mathrm{Ca}^{2+}$ Kinetics in Human Skeletal Muscle. Journal of Physiology, 589, 711-725. http://dx.doi.org/10.1113/jphysiol.2010.195982

[6] Pérez-Lizaur, A.B., Palacios, B. and Castro, A.L. (2008) Mexican System of Equivalent Foods. 3rd Edition, Fomento de Nutrición y Salud, Mexico City.

[7] Ministry of Health (2006) Mexican Oficial Standard NOM-043-SSA2-2005. Basic Health Services. Promotion and Health Education in Foods. Criteria to Provide Orientation. Diario Oficial de la Federación, 32-49.

[8] Morais-López, A., Rivero-de la Rosa, M.C., Galera-Martínez, R., Ros-Arnal, I., Herrero-Alvarez, M., Rodríguez-Martínez, G. and Getni, G. (2011) Calculation of the Energetic-Proteic Requirements for Nutritional Support in the Clinical Practice. Acta Pediátrica Española, 69, 211-216.

[9] Sterkowicz-Przybycień, K.L., Sterkowicz, S. and Zarów, R.T. (2011) Somatotype, Body Composition and Proportionally in Polish Top Greco-Roman Wrestlers. Journal of Human Kinetics, 28, 141-154. http://dx.doi.org/10.2478/v10078-011-0031-z

[10] Barbieri, D., Zaccagni, L., Cogo, A. and Gualdi-Russo, E. (2012) Body Composition and Somatotype of Experienced Mountain Climbers. High Altitude Medicine Biology, 13, 46-50. http://dx.doi.org/10.1089/ham.2011.1062

[11] Poliszczuk, T. and Broda, D. (2010) Somatic Constitution and the Ability to Mantain Dynamic Body Equilibrium in Girls Practicing Rhythmic Gymnastics. Pediatric Endocrinology, Diabetes and Metabolism, 16, 94-99.

[12] Cuk, I., Korencić, T., Tomazo-Ravnik, T., Pecek, M., Bucar, M. and Hraski, Z. (2007) Differences in Morphologic Characteristics between Top Level Gymnasts of Year 1933 and 2000. Collegium Antropologicum, 31, 613-619.

[13] Rivera, M.A. and Rivera-Brown, A. (1990) Morphofunctional Profile of Puertorican Gymnasts. Boletín de la Asociación Médica de Puerto Rico, 82, 347-352.

[14] Claessens, A.L., Veer, F.M., Stijnen, V., Lefevre, J., Maes, H., Steens, G. and Beunen, G. (1991) Anthropometric Characteristics of Outstanding Male and Female Gymnasts. Journal of Sports Sciences, 9, 53-74. http://dx.doi.org/10.1080/02640419108729855

[15] Claessens, A.L., Lefevre, J., Beunen, G. and Malina, R.M. (1999) The Contribution of Anthropometric Characteristics to Performance Scores in Elite Female Gymnasts. Journal of Sports Medicine and Physical Fitness, 39, 355-360.

[16] Claessens, A.L., Malina, R.M., Lefevre, J., Beunen, G., Stijnen, V., Maes, H. and Veer, F.M. (1992) Growth and Menarcheal Status of Elite Female Gymnasts. Medicine Science and Sports Exercice, 24, 755-763.

[17] Parm, A.L., Saar, M., Pärna, K., Jürimäe, J., Maasalu, K., Neissaar, I. and Jürimäe, T. (2011) Relationship between Anthropometric, Body Composition and Bone Mineral Parameters in 7 - 8-Year-Old Rhythmic Gymnasts Compared with Controls. Collegium Antropologicum, 35, 739-745.

[18] Burt, L.A., Naughton, G.A., Greene, D.A., Courteix, D.A. and Ducher, G. (2012) Non-Elite Gymnatics Participation Is Associated with Greater Bone Strength, Muscle Size and Function in Pre- and Early Pubertal Girls. Osteporosis International, 23, 1277-1286. http://dx.doi.org/10.1007/s00198-011-1677-z

[19] Erlandson, M.C., Kontulainen, S.A. and Baxter-Jones, A.D. (2011) Precompetitive and Recreational Gymnasts Have Greater Bone Density, Mass and Estimated Strength at the Distal Radius in Young Childhood. Osteoporosis Interna- 
tional, 22, 75-84. http://dx.doi.org/10.1007/s00198-010-1263-9

[20] Georgopoulos, N.A., Roupas, N.D., Theodoropoulou, A., Tsekouras, A., Vagenakis, A.G. and Markou, K.B. (2010) The Influence of Intensive Physical Training on Growth and Pubertal Development in Athletes. Annals of the New York Academy of Sciences, 1205, 39-44. http://dx.doi.org/10.1111/j.1749-6632.2010.05677.x

[21] Michopoulou, E., Avloniti, A., Kambas, A., Leontsini, D., Michalopoulou, M., Tournis, S. and Fatouros, I.G. (2011) Elite Premenarcheal Rhythmic Gymnasts Demonstrate Energy and Dietary Intake Deficiencies during Periods of Intense Training. Pediatric Exercise Sciences, 23, 560-572.

\author{
Abbreviations List \\ $\mathrm{BMC}=$ Bone mineral content \\ $\mathrm{BMD}=$ Bone mineral density \\ $\mathrm{BMI}=$ Body mass index \\ CoA $=$ Cortical area \\ CoC $=$ Cortical content \\ $\mathrm{CoD}=$ Cortical density \\ $\mathrm{FFM}=$ Free fat mass \\ $\mathrm{FM}=$ Fat mass \\ $\mathrm{SD}=$ Standard deviation \\ THD = Tukey Honestly Significant Difference \\ ToA $=$ Total bone area \\ ToC $=$ Total bone content \\ $\mathrm{ToD}=$ Total bone density \\ $\mathrm{x}=$ Average
}

